\title{
Cost and Productivity Ratios in Dual-Frame RDD Telephone Surveys
}

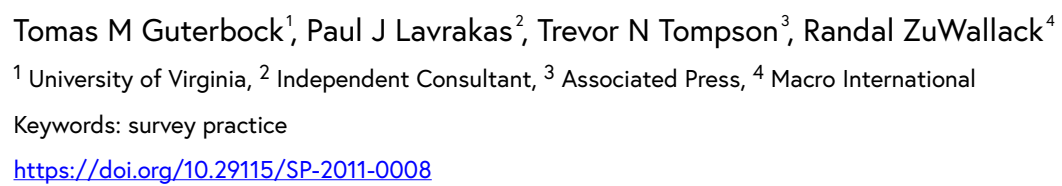

Survey Practice

Vol. 4, Issue 2, 2011

Cost and Productivity Ratios in Dual-Frame RDD Telephone Surveys

It has been clear from the first studies with RDD cell phone surveying in the U.S. that in most cases its cost is materially greater than the cost of similar surveying via RDD landline samples. During late 2009, a survey was conducted by the Cost Subcommittee of the AAPOR Cell Phone Task Force (AAPOR 2010) to gather data from a select group of telephone survey organizations in the U.S. This survey used a purposive sample of eight nationally known survey organizations (four commercial and four academic). Telephone interviews were conducted by members of the Cost subcommittee with a senior researcher at each organization who was knowledgeable about the cost information that was to be gathered. Each of those senior researchers then submitted a spreadsheet, assembled by her/his organization, containing available information about each of the dual telephone frame RDD surveys (cell and landline) that the organization had conducted. The results of this research are presented here.

Information was provided about 38 separate dual-frame RDD surveys. These surveys represented a mix of national, state, and local surveys. The type of information that was gathered about the RDD cell and RDD landline samples in these surveys included: (a) number of completions, (b) average length of a completion in minutes, (c) geography covered, (d) screening criteria, (e) completes per hour $(\mathrm{CPH})$, $(\mathrm{f})$ incentive amounts, and $(\mathrm{g})$ cost per interview (CPI). These data were used to generate various ratios for the analyses reported below.

Although it is acknowledged that the findings from this survey may not be representative of all recent dual frame RDD telephone surveying in the U.S., it appears to be the first time such cost data have been gathered from a wide set of survey organizations and about a relatively large number of dual frame telephone surveys. Thus, it is believed that the findings will do much more to inform, rather than misinform, the reader about the relative costs of cell phone surveying in the U.S. compared to landline surveying. Nevertheless, the reader is cautioned not to place undue confidence in these findings until cost reports from a much larger probability sample become available. 
Table 1 Productivity statistics and cost ratios for dual frame RDD surveys.

\begin{tabular}{|c|c|c|c|}
\hline Ratio (cell/landline) & SRHPC ratio & HPC ratio & Cost ratio \\
\hline Mean & 2.53 & 2.00 & 2.05 \\
\hline Minimum & 1.21 & 1.17 & 1.35 \\
\hline Maximum & 5.37 & 3.47 & 3.97 \\
\hline N & 26 & 26 & 20 \\
\hline Std. deviation & 1.02 & 0.63 & 0.77 \\
\hline
\end{tabular}

\section{Productivity and Cost Ratios in Current Dual Frame RDD Telephone Surveys in the U.S.}

The cost and productivity data gathered about the 38 dual frame RDD surveys support the conclusion that RDD cell phone surveying achieves lower productivity than $R D D$ landline surveying. To facilitate cost comparisons, we converted the reports of $\mathrm{CPH}$ into Hours per Completion [HPC]. The difference in HPC achieved for each frame accounts in large part for the cost ratio of cell phone to landline interviewing. We then calculated the hours per interview devoted only to screening and recruiting respondents [SRHPC] by subtracting from the HPC average the average interview length. The SRHPC is the primary component that will vary under different survey designs or conditions.

The differential in hours per completion (the HPC ratio) takes into account the time devoted to the actual interview. In some of the studies in our sample, the cell phone interview was deliberately shortened from the landline version; this makes for a lower HPC ratio than would have been obtained if interviews were of equal length in both frames. As shown in Table 1, the average HPC ratio was 2.0. Thus, on average across the 26 surveys for which these data were available, cell phone $R D D$ surveying took twice as long per completion as the $R D D$ landline; i.e., the completions per hour in the cell phone surveys came in at half the rate of the landline surveys.

Results for the ratio of screening and recruiting times (i.e., the SRHPC ratio) indicates that this time averages 2.53 times higher for the RDD cell phone samples than for RDD landline samples across all the surveys. No survey reported better productivity on the cell phone side compared to the landline side (i.e., this would be an SRHPC ratio of $<1.0$ ), and the lowest ratio was 1.21. The standard deviation of 1.0 indicates that, if the sample is representative, about two-thirds of dual frame surveys would have SRHPC ratios between 1.8 and 3.8. The maximum SRHPC ratio among the 26 surveys shown in Table 1 was 5.4 . 
Table 2 Means for all-cell (no screening) versus CPO-only surveys.

\begin{tabular}{|c|c|c|c|c|}
\hline \multicolumn{2}{|l|}{$\begin{array}{l}\text { Type of dual-frame } \\
\text { design }\end{array}$} & $\begin{array}{l}\text { Screening and recruiting hours per } \\
\text { completion }\end{array}$ & $\begin{array}{l}\text { Hours per } \\
\text { completion }\end{array}$ & $\begin{array}{l}\text { Overall cost per } \\
\text { Interview }\end{array}$ \\
\hline & & SRHPC ratio & HPC ratio & Cost ratio \\
\hline \multirow[t]{2}{*}{ All-cell designs } & Mean & 2.38 & 1.87 & 1.96 \\
\hline & $\mathrm{N}$ & 20 & 20 & 17 \\
\hline \multirow[t]{2}{*}{ CPO-only designs } & Mean & 3.03 & 2.45 & 2.60 \\
\hline & $\mathrm{N}$ & 6 & 6 & 3 \\
\hline
\end{tabular}

The cost ratio in Table 1 takes into account the cost of the phone number sample and cash incentives, generally used on the cell phone side only and set at $\$ 10$ per cell completion in the great majority of the surveys in this sample. With these added per-complete cost increments (small for most surveys), the average cost ratio rises slightly to 2.1 .

\section{Effects of a Cell Phone Only Dual-Frame Design}

Eligibility rates in the cell phone part are notably lower if a dual-frame design requires screening for cell-phone-only cases and dropping those reached via the cell phone sample that have dual phone service. About one in five of the surveys for which we gathered data used this "screened" or "CPO-only" dualframe design (for discussion, see AAPOR 2010, pp. 26-32). As shown in Table 2 , all three ratios are substantially lower in the "overlap" or "all-cell” design, when there is no screening for type of telephone service and all cell phones are considered to be qualified for inclusion on this factor. The SRHPC ratio for cell-only surveys was 3.0 , or about 30 percent higher, when contrasted with 2.3 for all-cell surveys. The average HPC ratio was 2.4 for the cell phone side in a cell-only survey compared to the companion landline survey, but 1.9 in all-cell surveys. The overall cost ratios varied in similar fashion, with the cell phone completions being nearly double the cost of landline completions in allcell surveys, whereas they were 2.6 times the cost in cell-only surveys.

\section{Cost Effects of the Geographic Area Covered}

The survey eligibility rate also is affected by the geographical location of the target population. When the study area is the entire nation, people who purchase their phone in one state and move to another remain eligible, at least from a geographic standpoint. When the survey geography is an entire state, then the eligible phone exchanges can be identified readily by area code alone. However, when the study area is a county, metro area, or another location not coincident with area code or prefix boundaries, then both landline and cell phone samples are less efficient for reaching persons in the defined study area. Moreover, the decrease in efficiency is likely greater for the cell phone RDD samples than for the list-assisted landline RDD samples. 
Slightly less than a third of the studies in our sample were local in their geography, but when we compared these with the state-wide and national studies, we found smaller differences in the cost ratios than we had expected. Although the differences were in the expected direction, with local studies having higher cost ratios, they were non-significant in our sample. The effect of sample geography on the cost ratios for dual-frame studies is an issue that bears further study.

\section{Summary of Cost Issues in U.S. RDD Cell Phone Surveys}

The survey industry in the U.S. now has had sufficient experience with dualframe telephone surveys combining RDD cell phone and RDD landline in order to have production and cost ratios estimated from empirical data. Based on reports from a heterogeneous set of more than 30 recent dual frame RDD surveys, it can be said with some confidence that in a typical dual-frame survey using an "all-cell" design (i.e., without screening for type of telephone service), that RDD cell phone interviewing will be, on average, about half as productive (per hour) as the RDD landline interviewing, and hence about double in cost per interview. If a Cell Phone Only design is used for the cell phone component in a dual frame design, the cell phone completions will cost, on average, approximately two-and-a-half times more than the landline completions. Nevertheless, these greater costs should not deter researchers from incorporating the RDD cell phone frame into their telephone surveys, as it is becoming increasingly difficult to achieve a representative general population sample using landline RDD alone.

Various features of a RDD dual frame survey, especially those that impact the working number rate, contact rate, eligibility rate, cooperation rate, type of dialing that can be deployed, use of advance mailings, or interview length, may cause the cost ratios between the cell phone and landline samples in that survey to vary from the ratios reported above. In particular, survey organizations that use predictive dialing on the landline side of a U.S. dual-frame survey will experience greater cost differentials because the increased cost-efficiency on the landline side cannot be achieved on the cell phone side because of legal restrictions. We also expected that dual-frame surveys in local areas generally would experience higher productivity and cost ratios than those using statewide or national sampling frames, but the evidence here is that productivity did not vary greatly with geography.

\section{Putting Costs into their Proper Context}

How much will it cost to convert a traditional landline RDD survey to a dual-frame survey? The answer depends on the size of the cell phone sample compared to the landline sample. For example, if an all-cell design is adopted (with a cost ratio expected to be about 2.0) and 15 percent of completed interviews are from the cell phone frame, then the overall production cost of the survey will be 15 percent higher than it would have been if all completes were drawn from the landline frame. If the new dual-frame design is screened 
or cell-only (expected cost ratio of 2.6) and 20 percent of completes are by cell phone, the production cost increases by 32 percent over landline RDD. (Increases in training, management or analysis costs are not here taken into account.)

Readers should keep in mind that the cost of RDD cell phone sampling must be considered within the context of optimizing the dual frame design. RDD cell phone samples in the U.S. are undertaken to improve coverage and bring into the sample members of groups that will (increasingly) be underrepresented in a RDD landline-only design. In addition, if a researcher chooses to minimize the number of cell phone completions out of a desire to minimize field costs, the survey may pay a penalty in statistical precision, because the realized sample will need to be adjusted with fairly large post-stratification weights. With a large design effect, the effective sample size may be reduced to the point where more completions are needed to maintain the desired level of precision. Interested readers should see Benford et al. (2009) for more on this issue and a discussion of the costs of various dual-frame designs measured against the resulting effective sample sizes.

\section{Future Expectations}

In the future, it is anticipated that data of the kind reported here could be used to develop and test a well articulated cost model for RDD cell phone interviewing that would allow practitioners to project the cost of a proposed $\mathrm{RDD}$ cell phone survey based on the known costs of RDD landline interviewing under similar study requirements. The data analyzed here could well be extended to cover a greater number of dual-frame studies, and the analysis of cost ratios could be extended to include a wider range of design features so as to better understand how each contributes to raising or lowering cell phone costs relative to landline costs.

As telephone systems and communications technologies in the U.S. continue to evolve, it is anticipated that the relative costs of RDD cell phone interviewing will change for the better. One trend that might lower the production and cost ratios is that as more people in the U.S. abandon their landlines, the working number density in the RDD landline frame will continue to decline, while the working number density will increase correspondingly for the RDD cell phone frame. Another trend is the increased adoption of the cell phone-only lifestyle (cf. Ehlen and Ehlen 2007). Cell phone-only persons appear more likely to answer cell phone calls from unknown callers and to use their phones in a fashion similar to the ways people have traditionally used household landline telephones. This trend could impact the contact and cooperation rates experienced in RDD cell phone interviewing in a favorable direction.

It is also probable that, as survey organizations and their interviewing staffs gain experience in calling cell phones, the productivity on the cell phone side may increase as techniques for sample management and for motivating respondents 
improve. Finally, it is possible that public directory listings for cell phone users may emerge in the future, and/or there may be ways found (using proprietary phone listings) to identify working number banks in cell phone exchanges through a modified form of the list-assisted sampled method. Such innovations could possibly lower the cell phone vs. landline production and cost ratios by increasing the working number rate in cell phone RDD surveys. (Unfortunately, however, attempts to date to apply the Mitofsky-Waksberg RDD method to cell phone sampling have not been successful in increasing productivity (see ZuWallack and Brown 2009.)

For the near future, however, the cost ratios are expected to remain within the general ranges reported here. The current and future patterns of telephone service and usage in the U.S. nonetheless make it imperative that telephone surveys continue to include cell phones in their sampling frames despite the additional costs that dual-frame designs entail.

\section{Acknowledgement}

The survey organizations were promised their names would not be disclosed. Our thanks to Robin Bebel of U.Va. CSR for assistance in the follow-up phase of the survey effort. 


\section{REFERENCES}

AAPOR Cell Phone Task Force. 2010. "New Considerations for Survey Researchers When Planning and Conducting RDD Telephone Surveys in the U.S. With Respondents Reached via Cell Phone Numbers.” American Association for Public Opinion Research. http://www.aapor.org/ Home.htm.

Benford, R., T. Tompson, C. Fleury, G. Feinberg, B. Feinberg, N. Speulda, and A. Weber. 2009. "Cell Phone and Landline - Considerations for Sample Design, Estimates, Weighting, and Costs.” Presented at the 64th Annual Conference of the American Association for Public Opinion Research; Hollywood FL; May 14.

Ehlen, J., and P. Ehlen. 2007. "Cellular-Only Substitution in the U.S. as Lifestyle Adoption: Implications for Telephone Survey Coverage.” Public Opinion Quarterly 71 (5).

ZuWallack, R., and J. Brown. 2009. "Mitofsky-Waksberg Sampling of Cell Phone Numbers.” Presented at the Annual Meetings of the American Association for Public Opinion Research, Hollywood FL, May. Hollywood FL, May. 